\title{
Evaluating Wind Power Potential for Electricity Production in Samawa City - Iraq
}

\author{
Abdul-Kareem Mahdi Salih ${ }^{1 *}$ and Maha Hatem Kamil ${ }^{2}$ \\ 'Department of Physics, College of Science, University of Thi-Qar, Iraq; \\ karimmahdisalih@yahoo.co.uk \\ ²University of Muthana, Iraq; mahaphy17@gmail.com
}

\begin{abstract}
Objectives: In the present paper, the wind power potential as a renewable energy source for electricity mass production in Samawa city - Southern Iraq is studied. Methods/Statistical Analysis: Wind speed, temperature, and the relative humidity are measured at height of 11 meters (anemometer height of Samawa meteorological station) for years (2012-2016) and feed as input data to computer program. Mathematical simulation performed to estimating this data and another essential parameters in the study as a function of height $(11 \mathrm{~m}<$ height $<80 \mathrm{~m})$, taking into consideration the effect of friction coefficient, temperature and relative humidity on density and wind speed. Finding: Wind speed and its frequency (probability density function) are two important factors to evaluating wind power potential represents. The study shows the minimum speed which suitable for electricity power production to be achieved at $34 \mathrm{~m}$ height average, but that insufficient for this purpose without achieving good frequency (probability density function) of the suitable speed. The study shows the daily mean of wind speed average characterized by good values and frequency at $75 \mathrm{~m}$ height. All the values to get over $5 \mathrm{~m} / \mathrm{s}$, and range between $5.14 \mathrm{~m} / \mathrm{s}$ to $8.23 \mathrm{~m} / \mathrm{s}$, that is considering good indication for wind power potential for electricity mass production in study site at least $75 \mathrm{~m}$ height. Application/Improvements: The utilization of wind speed for electricity mass production as a renewable energy in Samawa city-Southern Iraq can be verify at least (75 m) height approximately.
\end{abstract}

Keywords: Electricity Production, Iraq, Physics, Wind Energy

\section{Introduction}

The oil and gas are considered the main sources of energy in Iraq. The population growth leads to the increase of the use of these sources that caused atmospheric problems like air pollution. In Iraq, wind and solar energy are promising renewable sources of energy and environmentally friendly.

This study deals with the evaluation of the ability to utilize the wind energy for electricity production as a renewable energy in Samawa city, situated in Southern Iraq on latitudes (31.316) and longitude (45.283). Based on our knowledge, there was no detailed study concerning wind energy potential in this city. Due to the difficulty and unavailability of reliable climatic data at high-height related to Samawa city, mathematical simulation of different monthly rates data are measured at height of 11 meters (anemometer height in Meteorological station in Samawa city) to predict daily and annual rates. The behaviour of essential wind parameters (wind speed $(v)$, air density $(\rho)$, pressure $(p)$, power density $\left(P_{d}\right)$, Weibull probability density function (PDF) (frequency of wind speed), cumulative density function (CDF), maximum energy and most probable wind speed., friction coefficient, shape and scale parameters $(k, c)$ respectively, most probable wind speed $\left(v_{m p}\right)$, and the wind carrying maximum energy $\left(v_{E \max }\right)$ have been estimated according to the simulation. The simulation was carried out by a quick basic software computer program prepared in this study.

*Author for correspondence 


\section{Theory}

\subsection{Wind Power Density and Atmospheric Parameters Effect}

The estimation of wind power density $\left(P_{d}\right)$ in a unit of $W / m^{2}$ requires determining two important variables; the first one is air density $(\rho)$ in a unit of $\mathrm{kg} / \mathrm{m}^{3}$ and the second is wind speed $(v)$ in a unit of $\mathrm{m} / \mathrm{s}$, that is according to the following expression 1 :

$$
P_{d}=0.5 \rho v^{3}
$$

However, the actual power density extracted from wind by rotor blades estimated by the following equation?:

$$
P_{d}=0.5 C_{p} \rho v^{3}
$$

Where $\left(C_{p}\right)$ is the power coefficient representing the overall efficiency, whose theoretical maximum value equals 0.59 , while in practice it equals 0.52 ? The relation between temperature and pressure is expressed by Poisson equation as follows

$$
\frac{T_{1}}{T_{2}}=\left(\frac{P_{1}}{P_{2}}\right)^{R / C_{p}}
$$

Where, $\left(R / C_{P}\right)=0.286, C_{P}$ is the constant-pressure specific heat of air $T_{1}, T_{2}, P_{1}$ and $P_{2}$ are temperature and the pressure values at site 1 and 2 respectively. The equation which predicts the temperature as a function of height is expressed as follows

$$
T(z)=T_{g}-R_{a}\left(z-z_{g}\right)
$$

Where $T(z)$ the temperature at height $\mathrm{z}$ in meter above ground level is, $T_{g}$ is the temperature at ground level $z_{g}$, and $R_{a}$ is the temperature laps rate $\left(0.0065^{\circ} \mathrm{Cm}^{-1}\right)$. Dry air density $\left(\rho_{d}\right)$ can be determined in term of pressure and temperature by the following equation ${ }^{3}$ :

$$
\rho_{d}=\left(\frac{P_{o}}{R T}\right) \exp \left(\frac{-g z}{R T}\right)
$$

Where $P_{o}$ is the sea level atmosphere pressure (101325 Pascal), $g$ is the gravitational constant $(9.8 \mathrm{~m} / \mathrm{s})$, and $R$ is the universal gas constant for dry air $\left(287 \mathrm{~J} . \mathrm{Kg}^{-1} \cdot \mathrm{K}^{-1}\right)$. The variation of air density with the height given by the following expression ${ }^{5}$ :

$$
\rho=\rho_{o} \exp \left(-\frac{0.207 H_{m}}{3048}\right)
$$

Where $H_{m}$ is the site height in meters? Relative humidity is the amount of water vapor in the air relative to the maximum amount possible; it is defined mathematically by the following expression 6 :

$$
R H=\frac{e_{a}}{e_{s}(T)} \times 100 \%
$$

where $R H$ is the relative humidity, $e_{a}$ is the actual water vapor defined by the Antoine equation?:

$$
\log e_{a}=A-\left(\frac{B}{C+T}\right)
$$

where $A=8.07131, B=1730.63, C=233.426, e_{s}(T)$ is the saturation vapor pressure (Pascal) given by the following expression $\frac{6-7}{}$ :

$$
e_{s}(t)=\frac{e_{s o}}{p^{8}}
$$

Where, $P+\left(C_{0}+T\left(C_{1}+T\left(C_{2}+T\left(C_{3}+T\left(C_{4}+T\left(C_{5}+T\right.\right.\right.\right.\right.\right.$ $\left.\left.\left.\left.\left.\left.\left(C_{6}+T\left(C_{7}+T\left(C_{8}+T\left(C_{9}\right)\right)\right)\right)\right)\right)\right)\right)\right)\right)$,

$C_{o}=0.99999683, C_{1}=0.90826951 E-02$,

$C_{2}=0.78736169 E-04, C_{3}=0.61117958 E-06$,

$C_{4}=0.43884187 E-08, C_{5}=0.29883885 E-10$,

$C_{6}=0.21874425 E-12, C_{7}=0.17892321 E-14$,

$C_{8}=0.11112018 E-16, C_{9}=0.30994571 E-19$,

$e_{s o}=6.1078$.

The density of moist air written as the following 8 :

$$
\rho_{m}=\left(\frac{P}{R_{d} T}\right)\left(1-\frac{0.378 e_{a}}{P}\right)
$$

where $\rho_{m}$ is the moist density $\left(\mathrm{Kg} / \mathrm{m}^{3}\right), P=P_{d}+e_{a}$ is the total pressure, $P_{d}$ is the pressure of dry air (partial pressure), $R_{d}$ is the gas constant for dry air $(J / K g . K)$. The statistical calculation for annual mean of wind speedcan be performing by the relation:

$$
v_{m}=\frac{1}{n} \sum_{i=1}^{n} v_{i}
$$

Where $n$ the number of observations in the average period is, $v_{i}$ is the wind speed at the observation time. The wind power is proportionate to the speed cube; therefore, the root mean cube $(\mathrm{rmc})$ speed is defined in the following expression:

$$
v_{r m c}=\sqrt[3]{\frac{1}{n}} \sum_{i=1}^{n} v_{i}^{3}
$$

The variation of wind speed as a function of height in term of friction coefficient $\alpha$ is given by the following relation?:

$$
\left(\frac{v}{v_{i}}\right)=\left(\frac{H}{H_{i}}\right)^{\alpha}
$$


Where $v$ the wind speed at height is $H, v_{i}$ is the wind speed at height $H_{i}$, fraction coefficient can be calculated by the following equation $\underline{10}$ ?

$$
\alpha=\frac{0.37-0.088 \ln \left(v_{i}\right)}{1-0.088 \ln \left(H_{i}\right)}
$$

\subsection{Weibull Parameters Estimation Methods}

There are many mathematical methods to estimate the dimensionless shape parameter $(k)$ and the scale parameter $(c)^{\frac{11-13}{1}}$. In this study, the energy pattern factor method $\left(E_{p f}\right)$ has been used; it is related to the average data of wind speed, it is defined by the equation shown below ${ }^{13-14}$ :

$$
E_{p f}=\frac{\frac{1}{n} \sum_{i=1}^{n} v_{i}^{3}}{\left(\frac{1}{n \sum_{i=1}^{n} v_{i}}\right)^{3}}
$$

The Weibull shape and scale parameters are estimated by the below equations $s^{13-14}$ :

$$
\begin{aligned}
& k=1+\left(3.69 /\left(E_{p f}\right)^{2}\right) \\
& c=\frac{v_{m}}{\Gamma \cdot(1+1 / k)}
\end{aligned}
$$

Gamma function is given by:

$$
\Gamma(x)=\left(\sqrt{2 \pi x}(x-1) \cdot\left(e^{-x}\right)\left(1+\frac{1}{12} x+\frac{1}{288} x^{2}-\frac{139}{51840} x^{3}+\ldots\right)\right.
$$

The estimation of Weibull parameters as a function of height is given by the following relations ${ }^{15-16}$ :

$$
\begin{aligned}
& k_{z}=\frac{k_{y}}{1-0.0881 \ln (z / y)} \\
& c_{z}=c_{y}(z / y)^{l}
\end{aligned}
$$

Factor can be where $\mathrm{y}$ is the anemometer height, $\mathrm{z}$ is the desired height, $l$ is e estimated by the following relation:

$$
l=\left(0.37-0.088 \ln \left(c_{y}\right)\right.
$$

\subsection{Weibull Distribution Functions}

In general, the Weibull distribution can be used to estimate the wind speed distribution for a site, utilizing shape parameter which refers to the stability of wind and width of the distribution and the scale parameter $(c)(\mathrm{m} / \mathrm{s})$ which refers to the change in wind speed value ${ }^{12}$. There are two types of Weibull distribution function, the first one is the Weibull probability density function of wind speed as a good indication for frequency of speed given mathematically by the equation ${ }^{17}$ :

$$
f(v)=\left(\frac{k}{c}\right)\left(\frac{v}{c}\right)^{k-1} \exp \left(-\left(\frac{v}{c}\right)^{k}\right)
$$

The second is the cumulative density function indicating the time fraction or probability of the wind speed ${ }^{14}$. Weibull cumulative density function given mathematically as the following expression $\frac{18-19}{}$ :

$$
F(v)=1-\exp \left(-\left(\frac{v}{c}\right)^{k}\right)
$$

\subsection{Maximum Energy and Most Probable Wind Speed}

Two meaningful wind speeds for wind energy estimation are very useful to wind energy investor and assessors. These are called the most probable $\left(v_{m p}\right)$ and maximum energy carrying wind speed $\left(v_{E \max }\right)$ as the following equations $\boldsymbol{s}^{10,15,19}$

$$
\begin{aligned}
& v_{m p}=c \times\left(\frac{k-1}{k}\right)^{1 / k} \\
& v_{E \max }=c \times\left(\frac{k+2}{k}\right)^{1 / k}
\end{aligned}
$$

$\left(v_{m p}\right)$ Simply provides the most frequently occurring wind speed for a given wind probability distribution. The wind speed carrying maximum energy represents the wind speed that generates the maximum amount of wind energy.

\section{Results and Discussion}

A software computer program has been prepared in this study. Monthly mean of measured data of wind speed, temperature and relative humidity converted to daily mean and used as input into the program. All equations mentioned in section 2 have been solved in the program using the values of $\rho=1.225 \mathrm{~kg} / \mathrm{m}^{3}, C_{p}=0.5, p_{0}=101325 p a$, and for power density calculation used swept diameter $r=10 \mathrm{~m}$. The following studies are performing: 


\subsection{Minimum Height Estimation Ensures Suitable Wind Speed Average for Electricity Production}

Wind speed as monthly mean measured by Meteorological station of Samawa city ranges between $2 \mathrm{~m} / \mathrm{s}$ for $3.5 \mathrm{~m} / \mathrm{s}$ because they were measured at low height (11 meters) which is much lower than suitable limit of speed to ensure economically competitive or viable for projects of electricity production (wind speed value become economically competitive and suitable to this purpose at least $(5 \mathrm{~m} / \mathrm{s})$. Mathematical simulation concentrated on the estimation the minimum height at which wind speed approached to minimum limit required for electricity production. The simulation was carried with dual effect of temperature and humidity on electric power resulting from winds at different heights at the study site. Figure 1 represents the mathematical simulation of the relation between the wind speed and the height, where annual rate of wind speed was noticed to increase wherever height increased. The amount of increase relied on the value of density and pressure. Table 1 shows the minimum height estimation ensures suitable minimum wind speed average can be utilization for electricity production and the friction coefficient $(\alpha)$ for the study period (2012-2016). The calculations (Table1) and the Figure 1 shows that the annual mean of wind speed could approached or

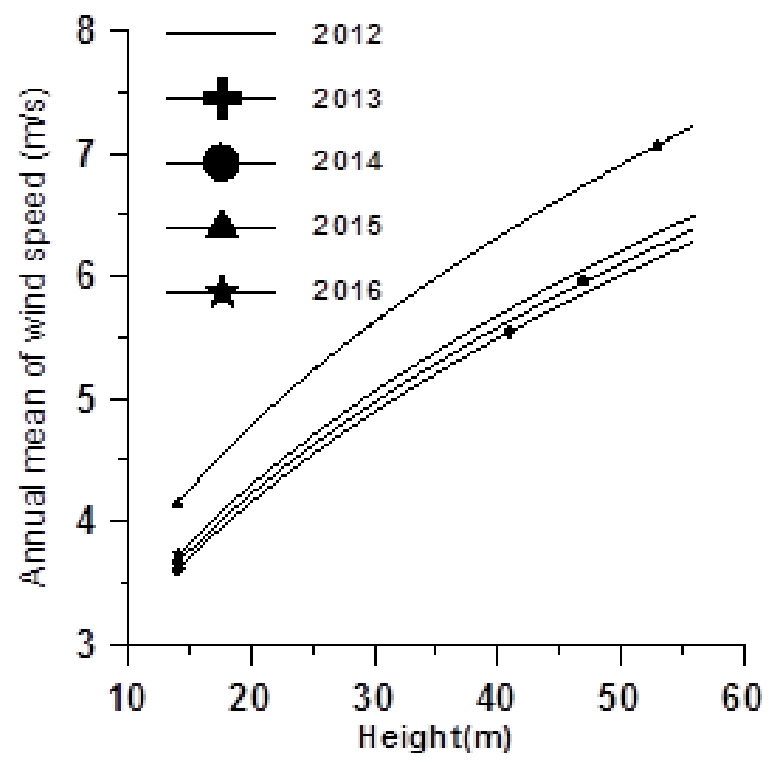

Figure 1. The annual mean of wind speed as a function of height for interval (2012-2016).

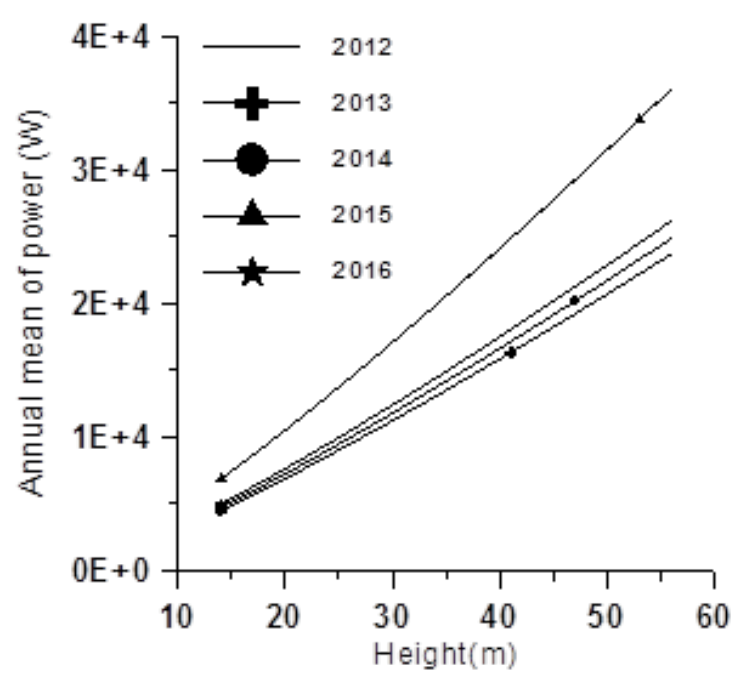

Figure 2. The annual mean of wind power as a function of height for interval (2012-2016).

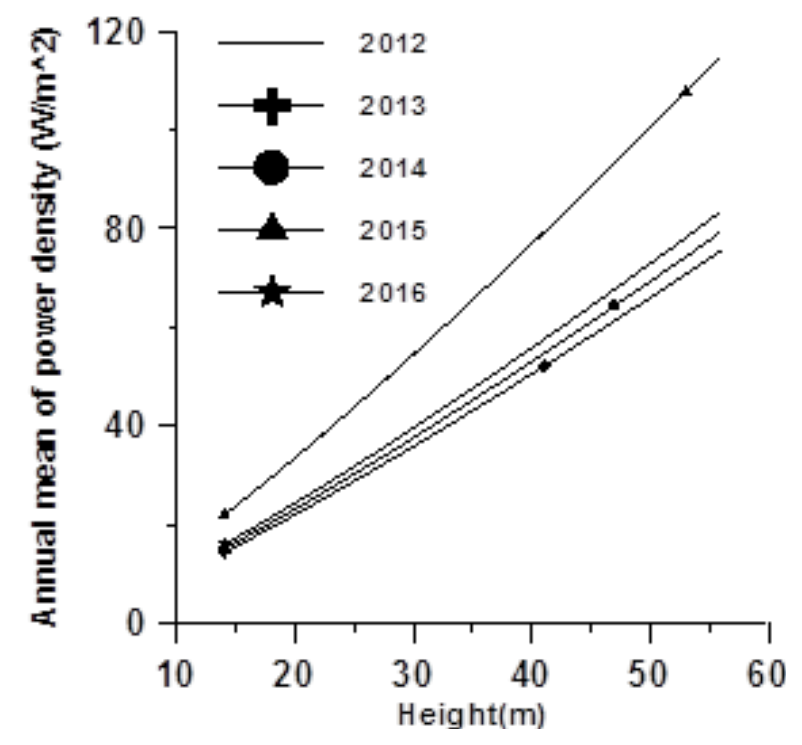

Figure 3. The annual mean of power density as a function of height for interval (2012-2016).

more $5 \mathrm{~m} / \mathrm{s}$ at an average height of study period $(34 \mathrm{~m})$ $(28 \mathrm{~m}, 40 \mathrm{~m}, 37 \mathrm{~m}, 27 \mathrm{~m}$, and $37 \mathrm{~m}$ for the years 2012 , 2013, 2014, 2015, and 2016 respectively). Figure 2 shows the increase of annual rate of power resulting from the increase of height for the study period that belonged to the increase of wind speed whenever the height increased as shown in Figure 1 \& Figure 3 declares the increase of annual rate values of power density with height increase for the study period. The reason attributed to the increase occurring in annual rates of power and wind speed with the height as shown in Figures 2 and 1 respectively. 
Table 1. Minimum heights ensure minimum suitable wind speed and friction coefficient values during study period

\begin{tabular}{|c|c|c|c|}
\hline Period & $\mathrm{H}(\mathbf{m})$ & $v_{m}(m / s)$ & $\alpha$ \\
\hline 2012 & 28 & 5.09 & 0.323 \\
\hline 2013 & 40 & 5.06 & 0.337 \\
\hline 2014 & 37 & 5.0 & 0.335 \\
\hline 2015 & 27 & 5.04 & 0.332 \\
\hline 2016 & 37 & 5.07 & 0.333 \\
\hline
\end{tabular}

\subsection{Assessment of Weibull Parameters and Weibull Density Functions}

The achievement of the minimum speed suitable for mass production of electricity power was insufficient for this purpose without achieving good frequency of the suitable speed. The wind speed frequency is a very important factor because of the wind speed variation. The variation in wind speed is most often described by the Weibull distribution. There are two important types of Weibull distribution; the first one is the Weibull probability density function, and the second is the Weibull cumulative density function. Weibull distribution assessment depends on the shape and scale Weibull parameters ( $\mathrm{k}$ and $\mathrm{c}$ ), it is an important task to know the wind speed frequency to select the suitable places for wind stations installation. In this part of the study, the shape and scale parameters have been estimated as a function of height for study period (2012-2016) using the energy pattern factor method (EPF) as illustrated in Table 2.

Table 2. Shape and scale parameters estimation as a function of height

\begin{tabular}{|c|c|c|c|c|}
\hline \multirow{2}{*}{ Period } & \multicolumn{2}{|c|}{$\mathrm{H}=\mathbf{3 5} \mathbf{~ m}$} & \multicolumn{2}{c|}{$\mathrm{H}=75 \mathrm{~m}$} \\
\cline { 2 - 5 } & $\mathbf{k}$ & $\mathrm{c}(\mathrm{m} / \mathbf{s})$ & $\mathrm{k}$ & $\mathrm{c}(\mathrm{m} / \mathrm{s})$ \\
\hline 2012 & 4.57 & 5.26 & 4.94 & 6.36 \\
\hline 2013 & 4.79 & 4.67 & 5.18 & 5.7 \\
\hline 2014 & 4.96 & 4.73 & 5.36 & 5.77 \\
\hline 2015 & 4.82 & 5.29 & 5.21 & 6.4 \\
\hline 2016 & 4.84 & 4.83 & 5.23 & 5.87 \\
\hline
\end{tabular}

Figure 4 represents the behavior of the probability density function and the cumulative density function for daily mean of wind speed for the study period at two different heights using EPF statistical method. The analysis and discussion of the (Figure 4) have been more explained by Table 3 .

Table (3a). Statistical analysis of Weibull density functions (PDF \& CDF)

\begin{tabular}{|c|c|c|c|c|c|}
\hline \multirow{3}{*}{$\begin{array}{l}\text { Study } \\
\text { Period }\end{array}$} & \multicolumn{5}{|c|}{$\mathrm{H}=35 \mathrm{~m}$} \\
\hline & \multicolumn{2}{|c|}{$\begin{array}{l}\text { Daily mean for suitable wind } \\
\text { speed for electricity mas } \\
\text { production }(\mathrm{m} / \mathrm{s})\end{array}$} & \multicolumn{2}{|c|}{$\begin{array}{l}\text { Daily mean for unsuitable } \\
\text { wind speed for electricity } \\
\text { mas production }(\mathrm{m} / \mathrm{s})\end{array}$} & \multirow[t]{2}{*}{ Max. value Of CDF } \\
\hline & $\begin{array}{c}\text { Speed rang } \\
(\mathrm{m} / \mathrm{s})\end{array}$ & (PDF) & $\begin{array}{c}\text { Speed rang } \\
(\mathrm{m} / \mathrm{s})\end{array}$ & $(\mathrm{PDF})$ & \\
\hline 2012 & $5-6.25$ & $0.33-0.18$ & $4.02-4.98$ & $0.25-0.32$ & 0.89 \\
\hline 2013 & $5.01-5.72$ & $0.33-0.16$ & $4.2-4.96$ & $0.37-0.33$ & 0.927 \\
\hline 2014 & $5-5.59$ & $0.35-0.21$ & $4.33-4.9$ & $0.39-0.35$ & 0.896 \\
\hline 2015 & $5-6.48$ & $0.342-0.15$ & $4.64-4.99$ & $0.32-0.34$ & 0.928 \\
\hline 2016 & $5.01-5.86$ & $0.35-0.16$ & $4.38-4.99$ & $0.37-0.35$ & 0.92 \\
\hline
\end{tabular}



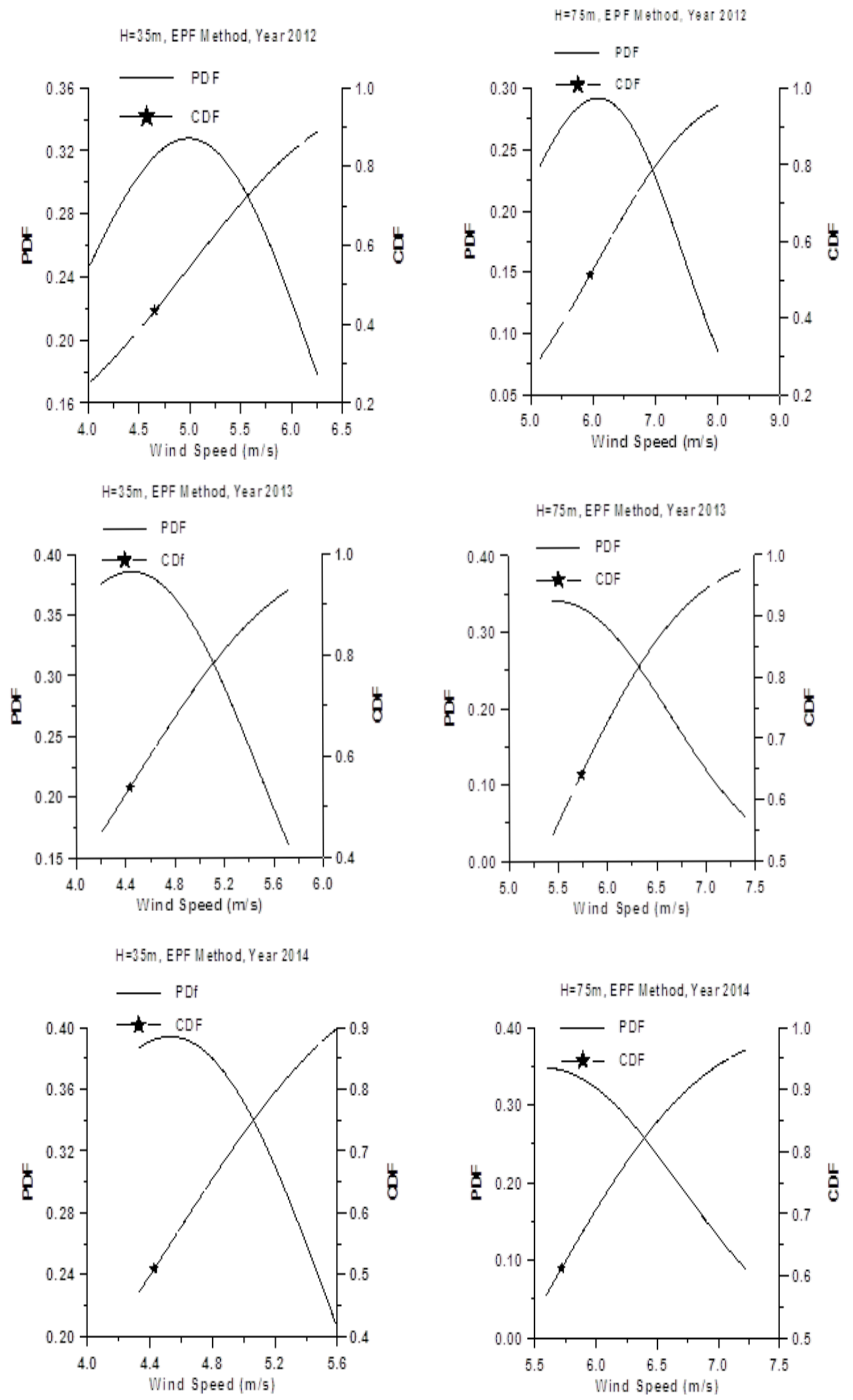

6 | Vol $11(32) \mid$ August 2018 | www.indjst.org

Indian Journal of Science and Technology 

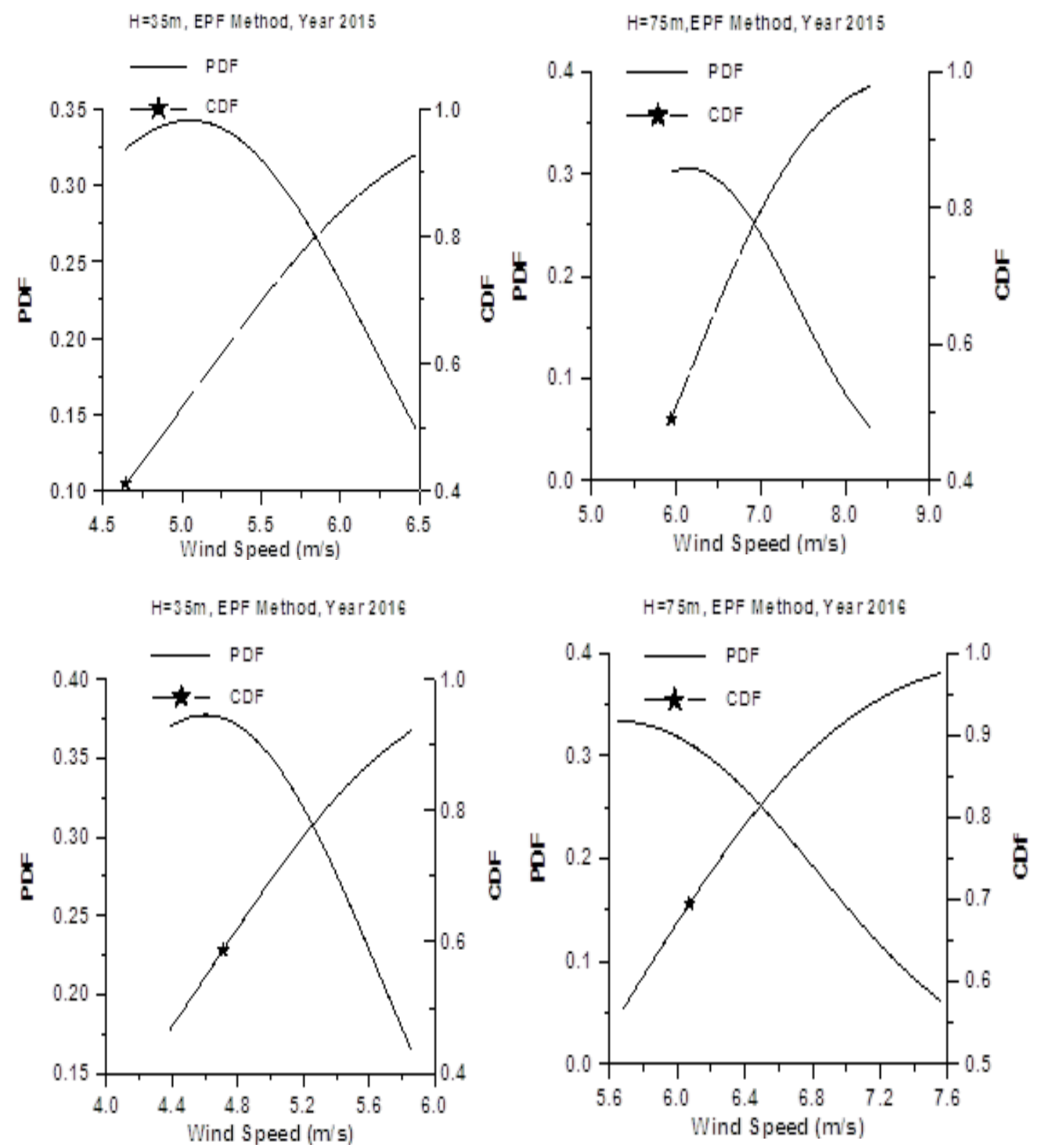

Figure 4. Behavior of probability and cumulative density functions at $35 \mathrm{~m}$ and 75 $\mathrm{m}$ height respectively for daily mean wind speed estimated by energy pattern factor methods for study period (2012-2016).

Table (3b). Statistical analysis of Weibull density functions (PDF \& CDF)

\begin{tabular}{|c|c|c|c|c|c|}
\hline & \multicolumn{5}{|c|}{$\mathrm{H}=75 \mathrm{~m}$} \\
\hline $\begin{array}{c}\text { Study } \\
\text { Period }\end{array}$ & $\begin{array}{c}\text { Daily mean for suitable wind } \\
\text { speed for electricity mas } \\
\text { production }(\mathrm{m} / \mathrm{s})\end{array}$ & $\begin{array}{c}\text { Daily mean for unsuitable } \\
\text { wind speed for electricity } \\
\text { mas production }(\mathrm{m} / \mathrm{s})\end{array}$ & Max. value Of CDF \\
\hline & $\begin{array}{c}\text { Speed rang } \\
(\mathrm{m} / \mathrm{s})\end{array}$ & $(\mathrm{PDF})$ & $\begin{array}{c}\text { Speed rang } \\
(\mathrm{m} / \mathrm{s})\end{array}$ & $(\mathrm{PDF})$ & \\
\hline 2012 & $5.14-8$ & $0.33-0.09$ & - & - & 0.955 \\
\hline 2013 & $5.44-7.4$ & $0.34-0.06$ & - & - & 0.967 \\
\hline 2014 & $5.6-7.22$ & $0.35-0.09$ & - & - & 0.964 \\
\hline 2015 & $5.9-8.23$ & $0.3-0.053$ & - & - & 0.982 \\
\hline 2016 & $5.65-7.6$ & $0.334-0.06$ & - & - & 0.976 \\
\hline
\end{tabular}


Table (3a) shows the statistical analysis of Weibull probability density function, it is declared that at $35 \mathrm{~m}$ height (Not: $35 \mathrm{~m}$ height choosing because it is the next upper height from the minimum limit illustrated in section 3-1) using the minimum limit of annual speed wind $(5 \mathrm{~m} / \mathrm{s})$ was still valid as it ranged between $5 \mathrm{~m} / \mathrm{s}$ for year 2012 to $6.48 \mathrm{~m} / \mathrm{s}$ for year 2015 through the study period, and characterized by frequency ranging between 0.33 to 0.35 . The actualization of speed above $5 \mathrm{~m} / \mathrm{s}$ is not enough to take decision to determine or select the site of wind energy stations instillation. Speed frequencies as well as speed value are important factors that must be given much care. The frequency of suitable and unsuitable speed are shown in Figure 4 and Table (3a), it is appear that at $35 \mathrm{~m}$ height there are some daily mean of speed ranging between $4.02 \mathrm{~m} / \mathrm{s}$ to $4.99 \mathrm{~m} / \mathrm{s}$ during 2012, 2015 respectively and frequencies ( 0.25 to 0.32$)$ as discouraging or unsuitable to mass production of electricity. While at $75 \mathrm{~m}$ height, appears that the daily mean of speed characterized by good values and frequency (no unsuitable daily mean of speed as shown in Table (3b), all the values to get over $5 \mathrm{~m} / \mathrm{s}$ and ranged between $5.14 \mathrm{~m} / \mathrm{s}$ during 2012 to $8.23 \mathrm{~m} / \mathrm{s}$ during 2015, in addition to encourager ratio of frequency. Then to insure that the optimization state to electricity mass production may use height $75 \mathrm{~m}$ at lest. Figure 4 shows the maximum value of cumulative density function of daily mean of speed as alternating between 0.89 to 0.928 during 2012, 2015 respectively at

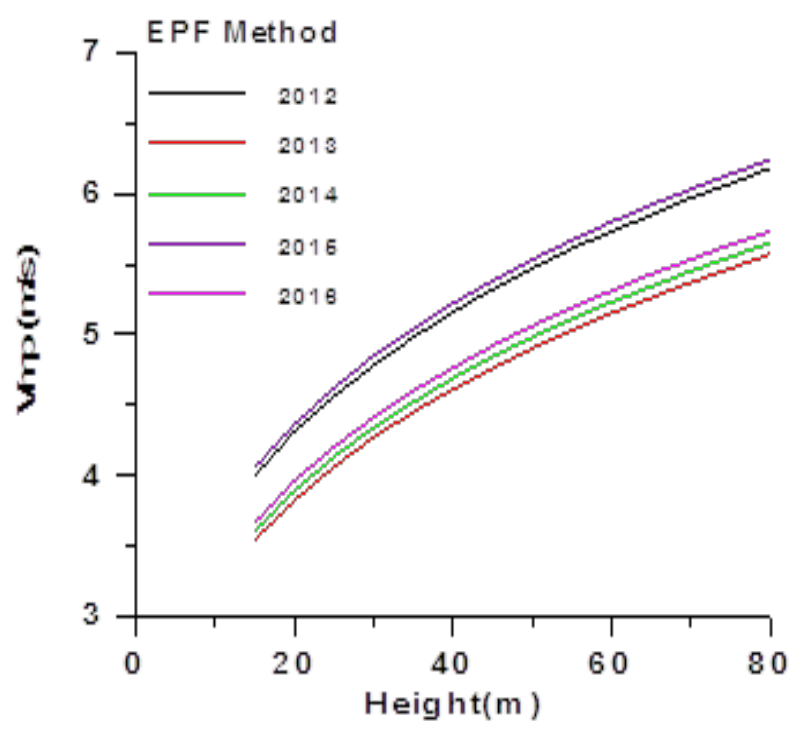

Figure 5. The most probable wind speed as a function of height for study interval (2012-2016) estimated by EPF method.
$35 \mathrm{~m}$ height as shown in Table (3a) and 0.955 to 0.982 during 2012, 2015 respectively at $75 \mathrm{~m}$ height as shown in Table (3b). That depended on the wind speed value at the period of study. Year 2015 distinguished by high cumulative density function, that is related to the high speed. Figures $5 \& 6$ show the behavior of the annual most probable wind speed and the annual wind speed carrying maximum energy estimated as a function of height for the study period (2012-2016). The figures clarify the increase of $\left(v_{m p}\right)$ and $\left(v_{E \max }\right)$ with the height. This relation is related to the behavior of wind speed values for each year of study period, which is an essential factor for estimating the scale and shape parameters used to estimate the $\left(v_{m p}\right)$ and $\left(v_{E \max }\right)$.

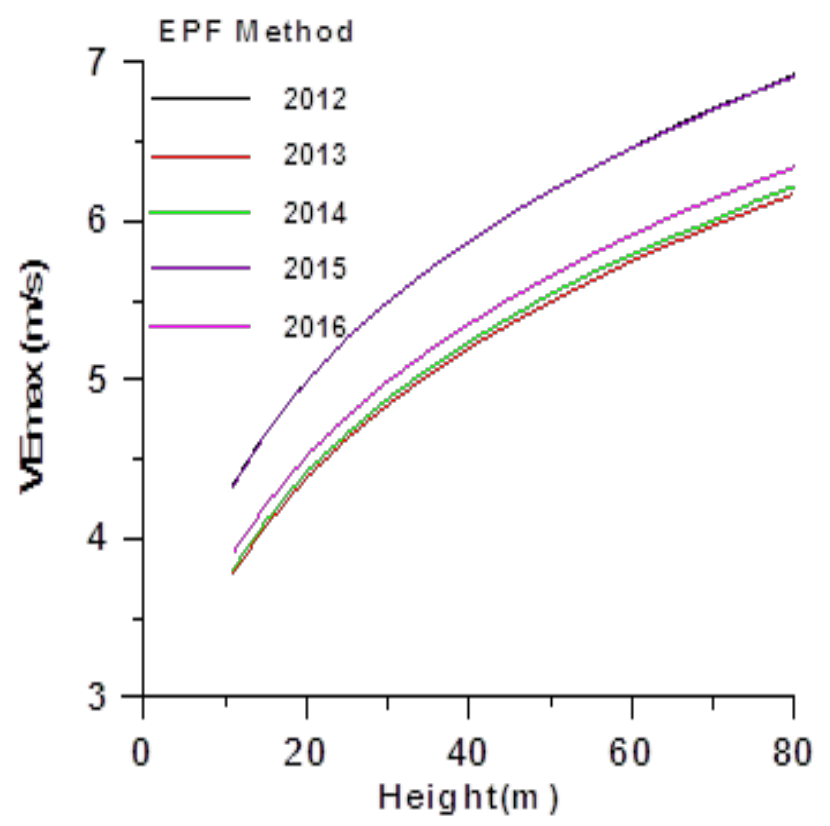

Figure 6. The wind speed carries maximum energy as a function of height for study interval (2012-2016) estimated by EPF method.

\section{Conclusions}

From the results of this study, the following conclusions could be mention as follows:

- The annual mean of wind speed in Samawa city approach to $5 \mathrm{~m} / \mathrm{s}$ at average height $(34 \mathrm{~m})$ approximately with low probability density function.

- The shape parameter calculations refer to good stability on wind speed at height $(75 \mathrm{~m})$ approximately. 
The Weibull probability density function and cumulative density function simulation refer to good appropriate frequency to acceptable wind speed ranges at $(75 \mathrm{~m})$ height.

- The utilization of wind speed for electricity mass production as a renewable energy in Samawa city can be verify at least $(75 \mathrm{~m})$ height, approximately.

\section{Reference}

1. Kira G. Harvesting the Wind: The Physics of Wind Turbines. Physics and Astronomy Comps Papers. 2005; p. 1-42.

2. Rupp C. Fundamental and Advanced Topics: In Wind Power. Civil and Environmental Engineering University of Windsor. 2011; p. 1-434.

3. Hau E. Wind turbines, Fundamentals, Technologies, Application, Economic, 2nd Edition. Springer-Verlag, Berlin. 2006.

4. Johnson GL. Wind energy system. Electronic Edition. Manhattan K.S. 2006; p. 1-449.

5. Jaime W. Historical development of the vapor equation from Dalton to Antoine. Journal of Phase Equilibria. 2001; 22:622-30. https://doi.org/10.1007/s11669-001-0026-x.

6. Valisala Oyj. Humidity conversion formulas. Calculation formulas for humidity. Vaisala, Finland. 2013; p. 1-17.

7. Tawhida A, Hisham M. The Relationship between relative humidity and the Dew point temperature in Khartoum State, Sudan. Journal of Applied and Industrial Science. 2013; 1(5):20-3.

8. Richard S. An Introduction to air density and density altitude Calculations. Shelquist Engineering. Colorado, USA. 2016.

9. Ahmad F, Ramesh B. Handbook of renewable energy Technology. University of Queensland: Australia, World Scientific Publishing Co. 2011.

10. Mehdi H, Dayan B, Masoud K. Evaluating wind energy Potential in Gorgan-Iran, using two methods of Weibull distribution Function. International Journal of Renewable Energy Development. 2016; 5(1):43-8.

11. Ayad A, Mohammed A, Firas A, Rawnak A. Weibull parameters and wind power Assessment for Three Locations in Iraq. Iraqi Journal Science. 2014; 55:729-40.

12. Kengne S, Oumarou H, Nganhou J. Modeling of Characteristics of Wind by Weibull distribution and Estimation of wind energy in Douala, Littoral Region of Cameroon. International Journal of Innovative Research in Science Engineering and Technology. 2016; 5(5):1-8.

13. Pulo A, Ricardo C, Carla F. Comparison of seven Numerical Methods for Determining Weibull parameters for wind energy generation in the Northeast Region of Brazil. Applied Energy. 2012; 89(1):395-400. https://doi. org/10.1016/j.apenergy.2011.08.003.

14. Indhumathy D, Seshaiah C, Sukkiramathi K. Estimation of Weibull parameters for wind speed calculation at Kanyakumari in India. International Journal of Innovative Research in science Engineering and Technology. 2014; 3(1):8340-5.

15. Kidmo D, Danew R, Djongyang N, Doka S. Statistical Analysis of Wind Speed Distribution Based on Six Weibull Methods for wind power Evaluation in Garoua, Cameron. Revue des Energies Renouvelable. 2015; 18(1):105-25.

16. Saeed J, Majid R, Yagob D, Marziyeh E, Kasra M, Ali M. Assessing wind energy Potential in Kurdistan Province, Iran. International Journal of Energy and Environmental Engineering. 2014; 5(2):1-11.

17. Emrah D, Salim C, Mehmet K. Finsler Geometry For TwoParameter Weibull distribution Function. Mathematical Problems in Engineering. 2017; p. 1-6.

18. Oyewola AM, Olanrewaju M, Ohunakin OS. Akinnawonu OO. Performance Evaluation of Wind turbines for Energy Generation in Niger Delta, Nigeria. Sustainable Energy Technologies and Assessments. 2014; 6:75-85. https://doi. org/10.1016/j.seta.2014.01.001.

19. Zohbi G, Hendrick P, Bouillard P. Evaluation du Potentiel Energie Eolienne au Liban. Revue des Energies Renouvelables. 2014; 17(1):83-96. 